\title{
SENDO ENFERMEIRA NO CENTRO DE TERAPIA INTENSIVA ${ }^{1}$
}

Adrina Katia Corrêa ${ }^{2}$

RESUMO: Encaminhando-me na perspectiva da fenomenologia, minha proposta é apreender, através dos depoimentos das enfermeiras que trabalham no CTI, os significados que as mesmas atribuem a essa vivência. Ao refletir sobre tais significados, aliando-os à minha experiência profissional, busco compreender o fenômeno ser enfermeira no CTI. Coletei depoimentos escritos das enfermeiras que atuavam no centro de terapia intensiva da Unidade de Emergência do Hospital das Clínicas da Faculdade de Medicina - Ribeirão Preto - USP, tendo como questão orientadora: o que significa para você ser enfermeira no CTI. Da análise desses depoimentos (MARTINS, 1992), emergiram as categorias temáticas, revelando que ser enfermeira no CTI é cuidar diretamente dos pacientes, é ter capacidade administrativa, é conviver com máquinas e equipamentos, exige muitos requisitos e o domínio de conhecimentos específicos, é desempenhar um trabalho importante, de responsabilidade e gratificante, bem como, conviver com situações limitantes e de estresse. A partir de uma reflexão compreensiva do modo de ser da enfermeira desse CTI, pretendo contribuir para busca de novas perspectivas do fazer, ampliando seu horizonte de possibilidades.

UNITERMOS: Enfermagem - Fenomenologia - Unidades de Terapia Intensiva

\section{O EMERGIR DESTE ESTUDO}

Após concluir o curso de Enfermagem, em 1989 , iniciei minha vida profissional como enfermeira assistencial no Centro de Terapia Intensiva (CTI) da Unidade de Emergência do Hospital das Clínicas da Faculdade de Medicina de Ribeirão Preto - Universidade de São Paulo. Esse era o local no qual eu desejava começar minhas atividades profissionais, por acreditar que teria maiores oportunidades de desenvolver habilidades e conhecimentos técnico-científicos, considerando a gravidade dos pacientes aí internados.

Com o passar do tempo, o trabalho mostrouse a mim como uma reprodução da prática já existente, sendo muito enfocado o fazer, com pouca ênfase na reflexão do que, como e porquê fazer.

Exercendo minha prática profissional no CTI, na busca de compreendê-la, refletia meu cotidiano de trabalho, indagando-me quanto às atividades que executava, minha relação com pacientes e colegas de trabalho, a importância do que fazia, os sentimentos e as realizações que experimentava.

E assim, apesar de vivenciar o mundo do CTI há quase cinco anos, o ser enfermeira mostrase a mim como algo a ser interrogado e desvelado a partir da experiência vivida pela enfermeira de CTI - essa enfermeira que sou e tantas outras. O que é isso, ser enfermeira em CTI?

$\mathrm{Na}$ busca de respostas a esse interrogar, a modalidade de pesquisa fenomenológica é um

1 - Trabalho adaptado da dissertação de mestrado "Sendo Enfermeira no Centro de terapia Intensiva", orientada pela profa Dra. Elizabeth R.M. do Valle, apresentada à Área Enfermagem Fundamental do Programa de Pós-graduação da Escola de Enfermagem de Ribeirão Preto-Universidade de São Pau'o, em abril de 1995.

2 - Enfermeira, Mestre em Enfermagem Fundamental. 
possível caminho, na medida em que se volta para a busca de compreensão dos fenómenos, enquanto são experienciados conscientemente no mundo-vida dos indivíduos.

Minha proposta é apreender, através dos depoimentos das enfermeiras que trabalham no CTI, os significados que as mesmas atribuem a essa vivência. Ao refletir sobre esses significados, aliando-os à minha experiéncia profissional busco compreender o fenómeno ser enfermeira no CTI.

\section{TRAJETÓRIA METODOLÓGICA - O ACESSO ÀS ENFERMEIRAS}

Consicierando minha interrogação - O que é isso, ser enfermeira em CTI - neste estudo vou à busca dessa compreensão, a partir dos depoimentos das enfermeiras que vivenciam o cotidiano no Centro de Terapia Intensiva da Unidade de Emergéncia do Hospital das Clínicas da Faculdade de Medicina de Ribeirão Preto - USP.

Foram coletados, em julho de 1994, sete depoimentos (quatro de enfermeiras atuantes e três de enfermeiras que haviam saído recentemente). Esses sete depoimentos mostraram-se suficientes para a análise, considerando a ocorrência de convergéncias nos discursos.

Num contato inicial, foram expostos a cada enfermeira o meu interesse em sua vivéncia no CTI e a finalidade da pesquisa. Foi, então, entregue a elas uma folha de papel almaço, contendo a questão orientadora deste estudo: $\mathbf{O}$ que significa para você ser enfermeira no CTI?

Considerando que esse setor é um local de freqüentes atividades, foi solicitado a cada enfermeira que a mesma, em sua residéncia ou outro local onde se sentisse tranqüila e à vontade, relatasse de forma espontânea, na folha de papel almaço que lhe foi entregue, que significado tem para ela a vivéncia de ser enfermeira no CTI.

\section{O SIGNIFICADO DE SER ENFERMEIRA NO CENTRO DE TERAPIA INTENSIVA}

Para desvelar o fenômeno em estudo, procedi à analise dos depoimentos obtidos, tendo em vista, o delineamento da pesquisa fenomenológica explicitado por MARTINS(1992). Ou seja, foram utilizados os três momentos da trajetória fenomenológica - a descrição, a redução e a compreensão.

A descrição fenomenológica compõe-se, na visão de Merleau-Ponty, por três elementos: a percepção, a consciência que se dirige para o mundo-vida, o sujeito que se vê capaz de experimentar o corpo-vivido através da consciéncia.

A redução fenomenológica, por sua vez, é o momento em que são selecionados as partes da descrição que são consideradas essenciais e aquelas que não o são, através da variação imaginativa. O pesquisador imagina cada parte como estando presente ou ausente na experiéncia, até que a descrição seja reduzida ao essencial para a existéncia da consciéncia da experiência.

A compreensão fenomenológica se dá em conjunto com a interpretaçăo. É o momento em que se tenta obter o significado essencial na descrição e na redução. O pesquisador assume o resultado da redução como um conjunto de asserções ou unidades de significado, que se mostram significativas para ele, apontando também para a experiência do sujeito, para a consciência que o sujeito tem do fenômeno. Inicialmente, as unidades de significado são assumidas na linguagem do sujeito que descreve o fenómeno (discurso ingênuo), sendo posteriormente transformadas em expressões próprias do discurso que sustentam o que está sendo buscado, por exemplo, um discurso psicológi$\mathrm{co}$, educacional, social. Finalmente é organizada uma sintese dessas unidades de significado encontradas, sendo buscadas, então, suas convergências, divergências e idiossincrasias.

Assim, num movimento de aproximação afastamento, realizei leituras atentas de cada depoimento, buscando os significados revelados nos discursos das enfermeiras, considerando a questão orientadora deste estudo. Daí emergiram as unidades significativas. Convergindo e divergindo tais unidades, na aproximação de um depoimento ao outro, articulando os significados, apreendi algumas categorias temáticas. Nesse momento, optei por recortar as 
unidades significativas dos depoimentos, as quais foram coladas numa folha de papel almaço, sendo agrupadas, o que facilitou minha análise e o emergir dessas categorias. Essas, enquanto possibilidade de compreensão, constituiram-se tendo em vista a minha perspectiva de enfermeira de CTI, revelando facetas do fenómeno em estudo, objeto de meu interrogar.

\subsection{As categorias temáticas}

Os significados atribuídos à vivência de ser enfermeira ao CTI revelam-se através das seguintes categorias tamáticas:

- Ser enfermeira no CTI é cuidar diretamente dos pacientes;

- Ser enfermeira no CTI é ter capacidade administrativa;

- Ser enfermeira no CTI é conviver com máquinas e equipamentos;

- Ser enfermeira no CTI exige muitos requisitos e o domínio de conhecimentos específicos:

- Ser enfermeira no CTI é desempenhar um trabalho importante, de responsabilidade e gratificante;

- Ser enfermeira no CTI é conviver com situações limitantes e de estresse.

Nesse momento, passo a: apresentar algumas unidades significativas ${ }^{3}$ de cada uma dessas categorias. Posteriormente serão feitas considerações, em conjunto, explicitadas na Estrutura Geral do Fenômeno.

- Ser enfermeira no CTI é cuidar diretamente dos pacientes

D3 - "(...) Ser enfermeira no CTI, representa (...) ter habilidades no cuidado direto ${ }^{4}$ de pacientes graves (...) É o que mais diferencia uma enfermeira de uma área aberta comparada à enfermeira do CTI."

D5 - "A assistência é direta, da enfermeira, (é em conjunto com os auxiliares), acho muito importante para melhor supervisão, recuperação do paciente e valorização do profissional."
- Ser enfermeira no CTI é ter capacidade administrativa

D3 - "É um elemento dentro da equipe que deve ter conhecimentos (...) administrativos para desenvolver tarefas, justificando-as; para organizar, coordenar e fazer cumprir todas as atribuiçőes de competéncia das várias categorias da enfermagem(...)"

D4 - "Ser enfermeiro no CTI significa estabelecer rotinas de atendimento (...) Avaliar desempenho do pessoal que deve ser qualificado.

Controlar as normas e rotinas, avaliar o nível do atendimento (...)"

D6 - "(...) Cabe ainda, a responsabilidade pelo planejamento e pela avaliação do cuidado de cada paciente, e delegar encargos aos demais membros da equipe de enfermagem."

-Ser enfermeira no CTI é conviver com máquinas e equipamentos

D4 - "Ser enfermeiro no CTI significa (...) colaborar na escolha de equipamentos e dos materiais."

D5 - "(...) tem que ter (...) visão global dos (...) equipamentos e manuseios."

D3 - "(...) Ser enfermeira no CTI, representa (...) habilitar-se no conhecimento e manuseio dos vários equipamentos utilizados numa terapia intensiva. É o que mais diferencia uma enfermeira de uma área aberta comparada à enfermeira de CTI."

-Ser enfermeira no CTI exige muitos requisitos e o domínio de conhecimentos específicos

D1 - "(...) os enfermeiros de unidades especializadas como o CTI, acumulam mais conhecimentos ao longo da carreira, pelas próprias exigéncias do setor. Por isso acredito serem estes profissionais diferenciados."

D3 - "É um elemento dentro da equipe que deve ter conhecimentos técnico-científicos (...)"

D4 - "A enfermeira deve ter"

- Conhecimento do serviço de CTI

- Facilidade de relacionamento e comunicação

3 - As unidades significativas vêm acompantsadas com o número dos depoimentos que as originaram (D1 - Depoimento 1 , D2 - Depoimento 2 e assim por diante).

4 - Os destaques nos depoimentos são da autora. 
- Capacidade de trabalho

- Liderança

- Iniciativa

- Didática (...)"

-Ser enfermeira no CTI é desempenhar um trabalho importante, de responsabilidade $e$ gratificante

D2 - "(...) Sei que posso dar uma assistência melhor ao paciente (...) É muito bom ver um paciente recuperando sua saúde e você saber que seu trabalho (...) colaborou para essa melhora."

D5 - "Quem toma conta do CTI são as enfermeiras."

D5 - "Pelas dificuldades que sempre vivenciamos, pela falta de funcionários, conseguimos a recuperação do paciente da melhor forma, o menos possivel de escaras, atendimento eficaz nas paradas cárdio-respiratórias, as aspirações freqüentes, etc (...)"

D7 - "Apesar desses problemas, gostei muito da experienncia e profissionalmente tenho a certeza que pude crescer."

- Ser enfermeira no CTI é conviver com situações limitantes e de estresse

D1 - "Pode parecer onipotência mas, muitas vezes, sinto-me responsável pela vida e pela morte de alguns pacientes, o que gera em mim um stress muito grande."

D1 - "No CTl existe uma dependência quase que total ou, muitas vezes, total do paciente em relação à enfermagem, o que faz com que o trabalho torne-se árduo, muitas vezes mecânico e repetitivo."

D7 - "(...) as condições de funcionamento do centro de terapia no que refere-se à instituição, corpo clínico e de enfermagem, deixaram muito a desejar (...) foram constantes os aspectos sócio-políticos e econômicos que estavam abalando o país e a manutenção do setor."

\subsection{A Estrutura Geral do Fenômeno}

Apreendo que as enfermeiras do CTI se sentem diferenciadas em comparação às enfermeiras que atuam em outros setores, o que está relacionado aos aspectos peculiares do seu trabalho como possuirem conhecimentos e habili- dades especificas, conciliarem as atividades de cuidar direto e administrar, refletindo a possibilidade de realizarem um trabalho abrangente.

O cuidar direto revela-se um modo significativo do existir profissional dessas enfermeiras, sendo enfocado como atividade prioritária, importante para melhorar a supervisão, a recuperação do paciente, a valorização e gratificação profissionais.

Além de prestarem cuidados diretos, essas enfermeiras que atuam em CTI também revelam, através de um discurso normativo, capacidade administrativa, que denota preocupação em manter a organização do setor.

A questão administrativa mostra-se, de maneira explícita, em alguns momentos, relacionada ao cuidar. Nesse sentido, há a preocupação em estabelecer rotinas, avaliar o nivel do atendimento e planejar o cuidado de cada paciente.

A realização de atividades administrativas por essas enfermeiras colocam-nas em contato com as pessoas com as quais trabalham (pessoal de enfermagem), no sentido de direcioná-las ao fazer esperado. Assim são mencionados aspectos como garantir cumprimento de atribuições e avaliação de desempenho.

Considerando as finalidades pré-determinadas de um CTI, os equipamentos apresentamse como instrumentos do trabalho cotidiano da enfermeira. Contudo, os depoimentos mostram, de modo geral, que os equipamentos estão ali e precisam ser manuseados, representando uma condição "sine qua non"do seu trabalho. Cabe salientar que um dos depoimentos (D3) revela que a enfermeira se sente diferenciada tanto por prestar cuidados diretos, como por conhecer e manusear os aparelhos. Entretanto, contrapondo em conjunto os depoimentos que se referem ao cuidar direto àqueles que dizem respeito à convivência com máquinas e equipamentos, apreendo que o cuidar direto é mais enfatizado.

Compreendo que as exigências do trabalho em CTI situam-se, de modo geral, nas dimensőes intelectual, motora e expressiva.

As dimensões intelectual e motora envolvem aspectos cognitivos, relativos aos conhecimentos técnico-científicos exigidos no desempenho das atividades específicas do CTI. A dimensão 
expressiva volta-se para os aspectos que envolvem as relações humanas (relacionamento, comunicaçăo, por exemplo).

Ser enfermeira no CTI envolve a realização de um trabalho permeado por ambiguidades aspectos gratificantes e limitantes estão presentes no seu mundo-vida.

Os sentimentos bons experimentados pelas enfermeiras de CTI mostram-se relacionados, em alguns momentos, à satisfação em colaborar na recuperaçăo do paciente. Acredito que essa satisfação torna-se revelante, considerando que,muitas vezes, o paciente está num limiar vida-morte. Nesse contexto, recuperar a saúde é recuperar a vida e a enfermeira convive com essa dimensăo do existir humano, o que dá ao seu trabalho um cunho de importáncia. $A$ satisfação com a melhora do paciente envolvese com a satisfação consigo mesma, reforçando o sentir-se competente.

Algumas enfermeiras vivenciam um sentimento de orgulho de si mesmas, percebendose como importantes e competentes, estando gratificadas com o trabalho que realizam. Embora manifestem tais sentimentos, elas também vislumbram situações limitantes e de estresse.

De modo geral, as limitações configuram-se de forma complexa, envolvendo desde os limites vida-morte até as questőes de åmbito institucional e do contexto da saúde. Essas limitações são apenas constatadas pelas enfermeiras, dada a sua complexidade.

Um aspecto que se mostra significativo é que os limites vida-morte pouco emergem nos relatos das enfermeiras, apesar da ocorrência da morte ser comum nesse ambiente de trabalho.

Considerando que as questões de âmbito político-económico se mostram em um depoimento apenas (D7), acredito que, de modo geral, as percepções das enfermeiras quanto ao seu fazer cotidiano pouco extrapolam a própria unidade, não englobando contextos mais amplos.

As enfermeiras desse CTI revelam valorizar suas atividades e, ao valorizá-las diferenciamse a si mesmas. Essas enfermeiras parecem buscar preencher de significados aquilo que fa- zem, seu existir profissional. Essa busca mostra-se, de modo geral, através de um discurso idealizado e envolvido por conceitos pré-estabelecidos. Nesse sentido, é comum o uso de "palavras prontas", ou seja, as enfermeiras utilizam-se de um vocabulário científico, composto por palavras-chaves - cuidar, planejar, organizar, dentre outras - e denominam o que fazem no cotidiano com tais palavras, permanecendo contudo, na superfície das mesmas, as quais, muitas vezes, năo dăo conta de responder àquilo mesmo que fazem.

Esse discurso idealizado também se faz presente, ao pontuarem as qualidades que devem possuir as enfermeiras de CTI e os sentimentos de gratificaçăo pelo trabalho, apesar da existência de limitações complexas, revelando com isso ums postura de super-valorizaçăo de seu existir profissional.

\section{REFLETINDO...SER ENFERMEIRA NO CENTRO DE TERAPIA INTENSIVA}

As facetas que se mostraram na análise dos depoimentos, clareando o fenómeno em estudo a minha experiência profissional nesse CTI, as leituras já realizadas, os pensamentos reelaborados agora se envolvem prestando-se a um refletir ${ }^{5}$ que traga compreensão do fenómeno ser enfermeira no CTI.

Refletir, nesse momento, não representa julgar o que se mostrou, buscar soluçőes, nem construir idealizaçőes, mas, é partir do concreto e a ele retornar com um novo olhar. Concreto esse que é o próprio existir profissional da enfermeira na cotidianidade do CTI. "(...)A reflexão não se retira do mundo em direção à unidade da consciência enquanto fundamento do mundo; ela toma distância para ver brotar as transcendências; ela distende os fios intencionais que nos ligam ao mundo para fazê-los aparecer (...)" (MERLEAU-PONTY, 1994,p.10).

$\mathrm{Na}$ perspectiva de refletir o fenómeno em estudo, uma das facetas que se fizeram presentes, é o cuidar direto.

5 - A reflexăo é aqui compreendida conforme o pensar de Merleau-Ponty, nas obras Fenomenologia da Percepçăo (1994) e Ciências do Homem e Fenomenologia (1973). 
Esse CTI é uma unidade que, apesar da gravidade dos pacientes, apresenta uma menor número de leitos, sendo possível à enfermeira, juntamente com o pessoal auxiliar, exercer 0 cuidado direto, năo somente nas situações de urgência, mas cotidianamente, seguindo a rotina já estabelecida. A enfermeira executa atividades desde as denominadas mais simples até as mais complexas - higiene do paciente, verificaçăo de sinais vitais, curativos, administraçăo de medicamentos, sondagens, punçőes venosas e arteriais, dentre outras.

A organização do cuidar também diferenciase da divisăo de trabalho por tarefas, amplamente empregada em outros setores do hospital, contudo, penso que o paciente ainda é visto da maneira compartimentalizada - o homem biológico, o homem psicológico, o homem social são tomados como dimensőes estanques.

Algumas vezes, ocorrem situaçőes nas quais o mundo da enfermeira e o mundo do paciente se interpenetram, coexistindo no compartilhar das vivências, na alegria da cura ou no sofrimento da morte. Essas experiências, porém, acabam năo sendo refletidas, exploradas pela enfermeira naquilo que significaram e acabam diluídas no fazer cotidiano.

De modo geral, acaba por predominar o cuidar biológico, com énfase na competéncia técnica da enfermeira. O domínio de um saber técnico pela mesma mantém-na apta ao cuidar, próxima ao paciente e ao pessoal auxiliar. Daí a valorizaçăo do cuidar direto pela enfermeira de CTI - ela é vista pelos demais e por si mesma como alguém que sabe fazê-lo.

Nesse sentido, a consciência da enfermeira se dirige para o cuidar direto, contudo, isso năo garante modificaçőes no seu olhar para o paciente. Compreendo que, apesar das modificações no organizaçăo do cuidar, diferenciandose da divisăo de trabalho por tarefas, bem como, estando a enfermeira exercendo o cuidar direto de forma mais intensa, a "filosofia" do cuidar não extrapolou ainda a dimensão da tarefa.

Retornando a organizaçăo do cuidar, a enfermeira envolve-se a tal ponto na rotina estabelecida (higienizar o paciente, dar a medicação, mudar o decúbito,...) que seu trabalho se entrelaça, sobremaneira, ao do pessoal auxiliar e técnico. Se, por um lado, como já comentado, a enfermeira se valoriza e é valorizadas nesse situaçăo, por outro lado, ela pode experimentar incertezas quanto às especificidades do seu próprio trabalho.

Em meu experienciar o mundo do CTI, já vivenciei situaçőes nas quais as enfermeiras se indagavam quanto à organizaçăo do cuidar: Até que ponto estamos apenas dividindo o trabalho com o pessoal auxiliar e técnico? Trata-se de um fazer mais completo? Quais seriam as atividades que nos distinguiriam dos demais, situando-nos em nossas especificidades? Essas indagações que, às vezes, emergiram nas reuniőes, representavam um questionamento de nosso existir profissional que poderia ter sido encaminhado a um refletir. Todavia, por não termos respostas imediatas, deixávamos de lado as inquietações e nos lançávamos no fazer cotidiano, permanecendo aí imersas, com poucas possibilidades de um despertar para outras perspectivas.

Nesse momento, intenciono-me com mais especificidade ao administrar, que também se revelou uma faceta significativa do fenómeno em estudo.

Tratando-se de um setor fechado, no qual a enfermeira presta, rotineiramente, cuidados diretos, o administrar encaminha-se na ótica de subsidiar as açőes do cuidar, restringindo-se, muitas vezes, ao estabelecimento e cumprimento de rotinas.

Sendo o cuidar o fio condutor do administrar, ambos estăo em contínua relação. $\mathrm{O}$ cuidar rotineiro e o administrar normativo se fotalecem mutuamente, presos à estrutura organizacional.

A administraçăo realizada pela enfermeira nesse CTI envolve o gerenciamento de pessoas. Nesse contexto, a enfermeira reproduz e se enquadra no discurso que busca os padrões únicos, os modelos hierárquicos estanques, que ditam as regras do comportamento, o que encaminha para a perspectiva do treinar, adestrar.

REZENDE (1990: 48) comentando MerleauPonty, explicita que "(...) em vez de falarmos do comportamento (behaviour) deveríamos falar 
de existência (...) o homem não se comporta mas existe, e quando apenas se comporta é porque ainda não cedeu à ordem propriamente humana da existência(...)"

A enfermeira nesse CTI não opta simplesmente por esse enquadramento comentado, mas está imersa nesse contexto que a encarcera, limitando seu sendo e seu vir a ser enfermeira. Essa é uma possibilidade mesma do existir humano, Refere, ainda, REZENDE(1990) que a existência humana é ambiqua, sendo vivida na dialética da apropriaçăo e da alienaçăo. A ameaça de viver sem perceber os sentidos que sua vida está tendo é constante para o homem.

Ainda encaminhando-me na perspectiva de refletir o ser enfermeira no CTI, lanço meu olhar para outro aspecto que se mostra significativo às enfermeiras - a convivência com máquinas e equipamentos.

Como já comentado, os depoimentos das enfermeiras revelam que as mesmas, de modo geral, buscam conhecer e manusear 0 arsenal tecnológico, embora năo o supervalorizem. Contudo, apreendo que a presença da máquina é apenas constatada pelas enfermeiras, năo sendo questionada a partir de prismas mais abrangentes, ou seja, não emergem questões éticas, políticas e económicas que a envolve.

Subsidiando o cuidar, o administrar, o lidar com as máquinas, as enfermeiras desse CTI relatam que necessitam possuir conhecimentos técnico-científicos e relativos à área expressiva.

Acredito que as enfermeiras de CTI, dada a natureza das atividades que fazem, considerando a gravidade dos pacientes dos quais cuidam diretamente, estão em constante desenvolvimento de sua capacidade de observação, destreza técnica, capacidade de agir com segurança em situações de emergência, bem como, manusear alguns equipamentos específicos. Essas são algumas das exigências do seu próprio trabalho, as quais, necessariamente, têm que ser aprimoradas e valorizadas pelas enfermeiras.

Porém, tais conhecimentos e habilidades, quando vistos apenas na sua imediaticidade, podem formar o mito da competência das enfermeiras de CTI.
Quando digo mito, não quero negar essa competéncia mas, colocá-la em outro plano. Como referi anteriormente, tal competência se faz necessária para a realização das atividades da enfermeiras, não se tratando de invenção. Contudo, às vezes, ela aparece super-valorizada, provavelmente, refletindo a ênfase nos aspectos bio-tecnológicos que caracterizam um CTI. Ou seja, em alguns momentos, ao serem reduzidos os paciente à vida biológica, as pessoas que manipulam, interferem e controlam esse viver săo extremamente valorizadas. Essas enfermeiras, então, tendo o domínio de alguns conhecimentos contrapõem com certa facilidade o "normal" do "anormal", o "esperado" do "inesperado". O nível biológico determina, prioritariamente, a busca de conhecimentos. $E$, essa idéia é retratada também pela literatura: "(...) É a enfermeira que observa o paciente por maior período de tempo. Por esse motivo, é freqüente que seja a primeira pessoa a diagnosticar as alterações nos sitemas fisiológicos principais"(LOPEZ,1973; 7).

Apesar de serem mencionados pelas enfermeiras os conhecimentos relativos à área expressiva, além do nível técnico-biológico, percebo uma perspectiva na qual tais conhecimentos são visualizados de maneira estanque. Questiono, entretanto, como na concreticidade do mundo-vida do CTI, tais conhecimentos se integram na totalidade do ser enfermeira.

O saber das enfermeiras assim posto, provavelmente, limita seus horizontes de compreensão daquilo mesmo que fazem, enquanto pessoas que coexistem, compartilhando, dentre outros, aspectos técnicos, políticos, económicos, éticos, humanos, os quais se integram no movimento do seu existir profissional.

As enfermeiras também expressam os sentimentos que têm quanto ao seu trabalho. Os aspectos gratificantes e limitantes estão de tal modo imbricados, interligados, constituindo o próprio ir e vir da dialética do existir humano.

Apreendo que os sentimentos de gratificaçăo que as enfermeiras manifestam pelo seu trabalho, estão muito relacionados a elas mesmas - săo as próprias enfermeiras que constituem, nutrem e reproduzem esses sentimentos. Por 
outro lado, como já comentado, os aspectos limitantes e de estresse que envolvem seu trabalho, dizem respeito, de modo geral, a questões complexas, apenas constatadas.

Compreendo que a complexidade dos aspectos limitantes do trabalho pode afastar as enfermeiras do seu enfrentamento, encaminhandoas para o sentimento de confiança em si mesmas, permanecendo numa situação onde predominam os sentimentos de gratificação. Se, por um lado, essa atitude as preservam de alguns aspectos difícieis, por outro lado, há a possibilidade de se adequarem às situações estabelecidas, as quais não são interrogadas. Nessa perspectiva é limitado o horizonte de possibilidades das enfermeiras, encaminhando seu cotidiano para o fazer carente de reflexão acerca do seu próprio contexto de trabalho e de si mesmas. Nesse momento, cabe citar MERLEAU-PONTY(1973:.40): "(...) a reflexão não é, absolutamente, a observação de um fato, é um esforço para compreender, não é a passividade de um sujeito que contempla sua vivência e, sim, o esforço de um sujeito que apreende a significação de sua experiência(...)"

A morte é um aspecto que merece reflexão. Acredito que, na sua ocorrência, a competência, os conhecimentos específicos, as habilida- des das enfermeiras são confrontadas com a finitude da existência humana. Compartilho com a idéia expressa por BOEMER "et al". (1989) essas pessoas sentem-se compromissadas com a vida e, ao preservá-la sentem-se gratificadas. Assim, a morte não surge enquanto possibilidade concreta da existência, uma vez que prevalece a idéia de que o CTI representa um mundo de luta pela vida.

O questionamento do seu próprio cotidiano pelas enfermeiras desse CTI poderia encaminhá-las da vivência na espera pré-reflexiva para a reflexão crítica desse cotidiano. Seria uma perspectiva de ultrapassar o cumprimento apenas de plantões que vão se sucedendo no diaa-dia para a compreensão daquilo mesmo que se faz, além do imediato. Nesse movimento podem aprofundar a consciência de si mesmas no mundo-vida do CTI, com vistas à apropriação de sua existência profissional e criação de caminhos que vislumbrem o alçance de novas perspectivas do fazer.

Minhas reflexões até aqui encaminhadas revelam meu inquietar com algumas facetas do fenômeno ser enfermeira no CTI. Tais reflexões, provavelmente, não se esgotaram. Deixo, ao término deste estudo, a idéia de inacabado, enquanto possibilidade mesma de outras reflexões.

\begin{abstract}
Considering the perspective of phenomenology, the author's proposal using testimonies of nurses working in the ITU (Intensive Therapy Unit) is to learn the meanings they attribute to this experience. Reflecting upon these meanings and allying them to her professional experience, the author searches to understand the phenomenon "being a nurse at an ITU". Written testimonies, from nurses working in the intensive therapy unit of the Emergency Unit of the "Hospital das Clínicas", College of Medicine of Ribeirão Preto, University of São Paulo, have been collected having as a guide question: "What does it mean to you to be a nurse in the ITU?" Analyzing those testimonies and according to MARTINS (1992), thematic categories emerged showing that being a nurse in the ITU is to care personally of the patients, have administrative capacity live together with machinery and equipment, master specific knowledge, perform important, gratifying and responsible functions, as well as to live with limiting and stressing situations. After a comprehensive reflection upon the mode of the being of the ITU nurses, the author's intention is to contribute to find new perspectives of "the doing", widening their horijons of possibilities.
\end{abstract}

KEYWORDS: Nurse - Nursing - Phenomenology - Intensive Care Units; 


\section{REFERÊNCIAS BIBLIOGRÁFICAS}

- BOEMER, M.R. et al. A idéia de mote em unidade de terapia intensiva: análise de depoimentos. $\mathbf{R}$. Gaúcha Enferm., v.10, n.2, p. 8-14, jul. 1989.

- LOPEZ, M. Manual de tratamento intensivo. Rio de Janeiro: Guanabara Koogan, 1973. cap.1, p.2-13: Centro de tratamento intensivo.

- MARTINS, J. Um enfoque fenomenológico do currículo: educação como poesis. São Paulo: Cortez, 1992.
- MERLEAU-PONTY, M. Ciências do homem e fenomenologia. Trad. de Salma T. Muchail. São Paulo: Martins Fontes, 1973.

\section{Fenomenologia da} percepção. Trad. de Carlos Alberto Ribeiro de Moura. São Paulo: Martins Fontes, 1994.

- REZENDE, A.M. Concepção fenomenológica da educação. São Paulo: Cortez, 1990. 